José Luis Moreno Pestaña

\section{Filosofía y sociología en Jesús Ibáñez: genealogía de un pensador crítico}

(Madrid, Siglo XXI, 2008)

Para quienes estudiamos a mediados de los años 1990 en la Facultad de Ciencias Políticas y Sociología de la Universidad Complutense de Madrid, Jesús Ibáñez era el nombre mítico de un, decían muchos de nuestros profesores, genial sociólogo, recién fallecido entonces, que teníamos la desgracia de no haber podido conocer y admirar en persona. Eso sí, al menos podíamos, o más bien debíamos, leerle porque, según nos decían también, su obra merecía convertirse en una de las principales referencias de nuestra formación como sociólogos, de la misma manera que lo había sido para la generación precedente, felizmente instruida en la década anterior con lbáñez como catedrático de técnicas de investigación social. He de admitir, sin embargo, que el esfuerzo que implicó su lectura, al menos en el caso de quien suscribe estas líneas, no se transformó en esa admiración mitificada que la Facultad deseaba transmitirnos, sino más bien en la decepción del que intenta comprender y descubre que carece de la disposición para hacerlo: deseando encontrar en él herramientas eminentemente técnicas - lo cual era lógico, como «padre» del grupo de discusión, la «técnica cualitativa» a la que más tiempo y atención se le prestaba en clase-, sus textos resultaban demasiado farragosos y eruditos. Incapaces de comprenderle realmente, Ibáñez se convirtió para muchos de nosotros en una cuenta pendiente en nuestra lista de lecturas, aún hoy no saldada convenientemente.

Aunque ignoro en buena medida si la posición con respecto a Ibáñez de las generaciones formadas posteriormente o en otras universidades españolas es similar, el libro de José Luis Moreno Pestaña se presenta como una gran ocasión para empezar a saldar nuestra deuda. $Y$ esto ocurre fundamentalmente porque el libro no es ni una biografía convencional —ni mucho menos laudatoria - ni un estudio sistemático —ni tan siquiera complaciente — de su obra y pensamiento. No se trata tampoco de un trabajo de filosofía, ni mucho menos de una guía de lectura de Más allá de la sociología o de Del algoritmo al sujeto. Estamos más bien ante una notable investigación sociológica que, trascendiendo biografía, pensamiento y obras, se esfuerza en comprender a Jesús Ibáñez en todas las dimensiones de su trayectoria. El resultado es más que sugerente pues, de principio a fin, el frustrado lector de lbáñez en el pasado $-\mathrm{y}$ estoy convencido de que, en cierto modo, también aquel que pretendía comprenderle sin dificultad, lugar en el que el propio Moreno Pestaña decía encontrarse hasta hace poco, tal como admite en la introducción del libro- toma conciencia de sus pretéritas dificultades de comprensión, y de los motivos que las provocaron, despertando un renovado interés por el introductor en España del grupo de discusión.

Y es que Ibáñez no aparece aquí descontextualizado, solo ante su figura y sus obras, sino precisamente como una personalidad fundamental para la comprensión ya no de su época 
y de los avatares intelectuales, ideológicos o políticos de su generación, sino sobre todo -y no es poco- de la fundación de la sociología española, así como, en términos más generales, de la historia más reciente de España. Ibáñez es, así, protagonista de estas tres dimensiones de una historia que, al situarle, como dirá de sí mismo Alfonso Ortí, en «el margen del centro» - $y$ al final de su vida en el propio centro, al menos en lo que se refiere al campo intelectual-, se convierte también en su propia historia. El libro de Moreno Pestaña es de este modo un muy solvente estudio de caso de sociología de los intelectuales: Ibáñez aparece en él como un intelectual clave inserto en una historia intelectual particular que la presente obra nos invita a recorrer, en primer lugar, recuperando a una generación sin la cual no sería posible comprender, al menos, la sociología española y, en segundo lugar, mediante una prosa muy comprensible y realmente agradable de leer, lo cual es siempre de agradecer.

Moreno Pestaña desmenuza la trayectoria de Jesús Ibáñez identificando al menos tres fases, marcadas por rupturas - ciertamente individuales, aunque en buena medida también colectivas- muy concretas que no sólo determinaron su carrera intelectual o académica -más bien habría que decir los retrasos producidos en ésta-, sino que, como el libro trata de demostrar, tuvieron una influencia fundamental, además de en sus compromisos políticos posteriores, sobre todo en las obras principales en las que quedó sintetizado su pensamiento, antes -la técnica del grupo de discusión-y después de alcanzar el reconocimiento académico - la «sociología crítica» transformada en «crítica de la sociología»-
Pasando sin excesivo detenimiento por sus orígenes, tanto de clase social -en el libro, citando a Alfonso Ortí, se nos dice que pertenecía a la «pequeña burguesía patrimonial rural» (p. 13) - como geográficos -era un provinciano que, con esfuerzo, logra estudiar con notorio éxito en Madrid, con lo que ello implica en términos de movilidad social ascendente-, Moreno Pestaña nos conduce a una primera fase en la trayectoria de Ibáñez. El estudiante de Ciencias Políticas y Económicas y joven becario reclutado para la élite del régimen franquista - joven intelectual en la órbita de Falange y a la sazón alumno y residente del Colegio Mayor César Carlos - aparece aquí encuadrado en los avatares políticos e intelectuales que dominaban en los primeros años 1950 el campo filosófico, al menos, madrileño que, con justicia, Moreno Pestaña opta por denominar «protosociología». El autor se refiere aquí a una nebulosa de intelectuales cuyas trayectorias, además de ayudar a comprender la aparición de una primera «filosofía social» ligada a una reconversión intelectual y política colectiva — «falangistas críticos» podrían denominarse-, de una manera u otra, habrían dejado sucesivamente su poso en lo que posteriormente identificaríamos como la sociología de Ibáñez. Partiendo de la confrontación de Ortega con la sociología, Moreno Pestaña nos presenta especialmente la influencia del pensamiento de Zubiri en el joven sociólogo. El autor se refiere igualmente, dentro de esta «protosociología», a otras figuras, como Javier Conde, ejemplo del intelectual falangista en plena reconversión, o Gómez Arboleya, que aparece probablemente como el principal exponente de la naciente sociología española. Ibáñez se encuentra aquí entre un grupo de jóvenes becarios 
selectos destinados, tras una «necesaria» formación en instituciones extranjeras $-\mathrm{y}$, en la mayoría de los casos, americanas-, a convertirse en las principales referencias académicas e intelectuales de las ciencias sociales españolas. Éste es precisamente el camino que seguirán algunos de sus compañeros de juventud —destaca aquí la figura de Salustiano del Campo-. Sin embargo, Ibáñez no alcanzará a dar ese paso: «convertido» a la crítica del régimen e implicado en los sucesos de febrero de 1956, detenido y juzgado, su previsible trayectoria académica se ve irremediablemente truncada por este primer hecho decisivo. Ibáñez sale así de la élite en la que se había formado y en la que parecía destinado a ocupar un espacio central.

Entramos aquí, precisamente, en una segunda fase de su trayectoria. Fuera de la academia - aunque, como Moreno Pestaña nos muestra, no del todo fuera de la élite académica e intelectual, pues siempre guardó en ella buenas relaciones y contactos que serán fundamentales años después-, Ibáñez se reorienta hacia el campo en el que es más conocido: la investigación de mercados. Autodidacta a la fuerza, Ibáñez aparece aquí como un gran innovador. De todos es conocida su principal aportación: el desarrollo del grupo de discusión, cuyos métodos y técnicas sistematizará años después en Más allá de la sociología, la versión publicada de su tesis doctoral. Sin embargo, el lector se topa aquí con una de las primeras paradojas de Ibáñez: como nos indica con claridad Moreno Pestaña, a pesar de haberle dado fama a posteriori, sabemos muy poco de las, dicen, muchas investigaciones de campo que en aquellos años —en las décadas de 1960 y
1970 - realizó. El «padre» del grupo de discusión, una vez obtenido años después el reconocimiento académico, en cierto modo, le niega a la sociología española el conocimiento de sus trabajos empíricos: como nos dice el autor, hay muy pocas referencias a éstos en los libros de Ibáñez.

Es, en fin, estudiando la tercera fase de su trayectoria como Moreno Pestaña alcanza a darnos algunas pistas que nos permiten obtener respuestas, siempre parciales, a esta paradoja. Así, Ibáñez obtiene finalmente un reconocimiento tardío de su trayectoria entrando en la academia de la mano de Salustiano del Campo, su antiguo compañero situado en el centro del campo sociológico español, quien le dirige su tesis doctoral y, años después, le facilitará la obtención de la cátedra de métodos y técnicas de investigación social. La publicación de ambos trabajos - la tesis en Más allá de la sociología y la memoria de cátedra en Del algoritmo al sujeto- otorgará definitivamente a Ibáñez todo el reconocimiento intelectual.

Considero que hay en el libro de Moreno Pestaña, al menos, dos cuestiones fundamentales referidas a esta dilatada última fase. La primera es la integración de lbáñez en un campo concreto, la sociología española de los años 1970 y 1980 , sus divisiones administrativas y sus fracturas ideológicas. Como muy bien nos describe el autor, la sociología española —en la época, pero incluso aún hoy- posee todas las características de un campo intelectual periférico y dominado en el que las divisiones del campo se hacen a partir de la importación de las divisiones de éste en las sociologías dominantes o, más bien, en la interpretación que 
desde España se hace de aquéllas. El resultado es un sistema de reconocimientos en el que no sólo no prima la investigación empírica, aun dotada de un muy serio bagaje metodológico como la realizada por Ibáñez en el terreno de la investigación de mercados, sino que ésta se ve irremediablemente subordinada por la profusa cita de autores extranjeros que otorguen sentido al campo «importado» y a sus correspondientes divisiones. Las memorias de cátedra, y aun las tesis doctorales, al menos en la época, son muestra de esta exigencia. A pesar de su trayectoria, Ibáñez, revolucionario en la técnica y la metodología, acabará adaptándose perfectamente a dichas prácticas, «olvidando» prácticamente en sus textos su reputada experiencia empírica. Se comprende así por qué Ibáñez le resultaba tan farragoso al estudiante de los años 1990 que deseaba encontrar en él al técnico del grupo de discusión. Se comprende también en qué medida, en un campo intelectual «del centro», Ibáñez podría haber sido un gran teórico a partir de su trabajo empírico. En España, en cambio, los trabajos que consagran a Ibáñez acaban siendo los de un lector, sin duda de gran nivel, de autores que ocupan el centro. Uno se plantea así en qué medida, en un campo periférico, y en aquellos momentos, esto era a lo máximo a lo que podía aspirar un sociólogo español.

La segunda cuestión que destacaría es consecuencia de lo dicho anteriormente: el regreso de Ibáñez a la filosofía en su última época y el contraste que esto supone con su trayectoria anterior. Moreno Pestaña nos presenta (sintetizado en un claro cuadro resumen, p. 132), creo que con argumentos convincentes, a un Jesús lbáñez consagrado académica e intelectual- mente, e incluso convertido en un referente político, que sin embargo abandona toda su, como la denomina el autor, «autonomía creativa», aquella que atravesó tanto la práctica del grupo de discusión como su síntesis teórica. Es en este contexto en el que, de nuevo, comprende mejor la figura de lbáñez el estudiante de los años 1990: la combinación de la mitificación de su figura tras su muerte con sus últimos textos, que se nos invitaba a leer entonces, parece deberse más a su elevada posición en el campo que a la originalidad —decreciente, según Moreno Pestaña- de su postrera aportación a la investigación sociológica.

En realidad, el libro de Moreno Pestaña invita a saber mucho más. La conjunción de su brevedad (apenas 135 páginas de texto) con la multitud de cuestiones que deja abiertas puede así despertar en el lector un nuevo interés, no sólo por Ibáñez y sus obras más conocidas, sino especialmente por la generación de intelectuales cuyas trayectorias están estudiando, por el momento con notoria solvencia, desde el grupo de investigación de la Universidad de Cádiz al que pertenece el autor. Se trata, creo, de un ejercicio ciertamente necesario en cuanto que extremadamente útil, a fuer de aclaratorio, para la comprensión de la historia - no sólo intelectual, aunque también- más reciente de España. Así, el libro de Moreno Pestaña invita sobre todo a esperar, con gran interés, las futuras publicaciones a las que dé lugar el proyecto sobre el campo filosófico español que desde Cádiz - es decir, en cierto modo, desde la periferiase está llevando a cabo en torno a las figuras intelectuales -es decir, las que ocuparon el centro o estuvieron cerca de éste- más noto- 
rias de las generaciones formadas en el régimen franquista cuya influencia se extiende prácticamente hasta nuestros días. Al menos esta primera contribución demuestra de qué manera el estudio sociológico del campo filosófico no es sino el conocimiento avanzado - desvelando las contradicciones, luchas de poder, mutaciones ideológicas o posicionamientos estratégicos individuales y colectivos- de la historia intelectual, aunque también política, de España. Historia de la sociología española, historia intelectual e historia reciente de España en las que resulta fundamental seguir profundizando de la manera crítica y desprovista de prejuicios —en lo que se refiere, ante todo, a mostrar las idas y venidas ideológicas de sus protagonistas- en que lo hace el libro de Moreno Pestaña con respecto a Jesús Ibáñez.

Además, el análisis de Moreno Pestaña tiene la virtud de contribuir a despertar una renovada atracción por un autor fundamental para la sociología española como es Jesús Ibáñez. Hoy, cuando la sociología española, sin abandonar del todo sus viejas configuraciones propias de un campo dominado - hoy las importaciones son casi exclusivamente anglosajonas-, va produciendo más y mejores trabajos profesionales de investigación empírica, el libro de Moreno Pestaña mueve el deseo de ver publicados, de alguna manera, los que suponemos numerosos informes de investigación realizados por lbáñez, o al menos poder acceder a ellos con mayor facilidad. Como hemos visto, el trabajo de Moreno Pestaña permite comprender bien por qué Ibáñez se refiere poco a ellos. Sin embargo, estoy convencido $-\mathrm{y}$ me da la impresión de que el autor del libro también lo está- de que poseen un valor incalculable, además de como verdaderas herramientas técnicas —son éstas las que buscábamos al intentar leerle-, como pruebas de la investigación realizada en aquella época y de sus resultados, que no son sino un exponente fundamental tanto de la sociología española como de la historia más reciente de España.

Alberto MARTÍN PÉREZ

\section{Andrew Webster y Nik Brown}

\author{
New Medical Technologies \\ and Society. Reordering Life
}

(Londres, Polity Press, 2004)

\section{Andrew Webster \\ Health, Technology and Society. A Sociological Critique}

(Nueva York, Palgrave Macmillan, 2007)

¿Dónde se encuentra actualmente la Sociología de la Ciencia (y, de forma más general, el campo interdisciplinar de los Estudios de Ciencia y Tecnología, o STS)? ¿Hacia qué terrenos la ha conducido en los últimos tiempos su peregrinaje, por tomar el subtítulo de aquella compilación de artículos de Michael Mulkay, Sociology of Science: a sociological pilgrimage? Tras la intensa y agitada historia de la disciplina durante las últimas tres décadas del si- 